\title{
Thyrotoxic Periodic Paralysis In A Nigerian: A Case Report
}

\author{
N. A. Ajayi \\ Department of Internal Medicine, Federal Teaching Hospital, Abakaliki, Nigeria.
}

\begin{abstract}
Abstarct : Thyrotoxic periodic paralysis is a disorder in which there are episodes of muscle weakness in people with high levels of thyroid hormones. It is a channelopathy characterized by an abnormality in the $\mathrm{Na}^{+} / \mathrm{K}+$ ATPase pump due to the effect of excess thyroid hormones which cause an intracellular shift of potassium leading to hypokalaemia in the presence of normal total body potassium ${ }^{1}$. The commonest cause of hyperthyroidism in these patients is Grave's disease ${ }^{2,3,4}$ but other causes have also been described ${ }^{5,6 .}$ It is commoner in males than females unlike in other thyroid disorders ${ }^{7,89 .}$. The modes of presentation include limb paralysis, dyspnoea, dysphagia, ophthalmoplegia, and cardiac rhythm disturbances. The attacks are potentially life threatening ${ }^{10,11,12}$ but patients are normal between attacks. The condition is rare and is seen most commonly in Asian ${ }^{13,14,15}$ and Latin American men ${ }^{16,17}$ but has also been noted in caucassians ${ }^{18,19,20}$ and African Americans ${ }^{21,22}$. This case is reported to alert physicians to the occurrence of this rare but potentially life threatening disorder in a Nigerian patient.
\end{abstract}

Key Words: Thyrotoxic periodic paralysis. Nigerian. Male.

\section{Introduction:}

CASE REPORT: A 35year old businessman came to our outpatient clinic with a history of recurrent inability to walk which started two days prior to presentation at a frequency of once daily. Each episode was preceded by muscle aches in the lower limbs of about a day's duration and started a few hours after the ingestion of a heavy meal of rice. The first episode of lower limb weakness happened suddenly while he was walking. His legs suddenly gave way under him forcing him to fall with the buttocks. His attempts to stand up failed and he had to drag himself along on the buttocks with the help of his hands. Later that evening, he could not turn in bed. The lower limb weakness lasted about 8hours before resolving completely spontaneously. The second episode occurred by mid morning the next day while walking from his car to his house. He again suddenly lost control of his legs and fell on his buttocks. There was neither loss of consciousness nor seizures. There was no preceding trauma, headache, backache, diarrhoea, or vomiting. He was not on any medication prior to the illness and there was no family history of intermittent paralysis. He had been loosing been despite increased appetite in the past three months. He was irritable, sweated excessively, and had heat intolerance, reduced effort tolerance, and disturbing palpitations.

Examination showed a moderately wasted fidgety young man who was sweating profusely and had fine tremors of the outstretched hands. He had a small diffuse firm non tender thyroid swelling as well as bilateral proptosis with retraction of the upper eye lids and mild conjunctival redness. The nails and skin over the legs were normal.

His pulse was regular at 120beats/minute and was of good volume. The blood pressure was $140 / 90 \mathrm{mmHg}$. The apex beat was felt at the $5^{\text {th }}$ left intercostals space lateral to the mid clavicular line. The heart sounds were normal but there was an apical soft systolic murmur. The muscle tone was normal and he was fully ambulant. A working diagnosis of thyrotoxic periodic paralysis was made and he was started on tabs propranolol 40mg twice daily.

His thyroid function tests showed elevated thyroid hormones and a depressed thyroid stimulating (TSH) hormone level as follows:

T3 $\quad 5.5 \mathrm{ng} / \mathrm{ml}(0.6-2.1)$

T4 $24.0 \mathrm{ug} / \mathrm{ml}(4.2-12.0)$

TSH $\quad 0.1 \mathrm{iu} / \mathrm{ml} \quad(0.4-5.2)$

His blood also tested positive for antithyroid peroxidase and antithyroglobulin antibodies.

His serum potassium which was done after the resolution of the paralysis was normal at $4.0 \mathrm{~mm} / \mathrm{L}$

A final diagnosis of Grave's disease with periodic paralysis was made.

Tab carbimazole was added to his treatment and propranolol was continued. He has improved substantially and has not had another attack of paralysis since then. His weight has increased from $64 \mathrm{~kg}$ to $74 \mathrm{~kg}$ in the last 4 months. Most of his other symptoms have abated. 


\section{Discussion:}

Thyrotoxic periodic paralysis is found mainly in Asian men and has also been described in Latin Americans, Caucasians, and African Americans. Its occurrence in this patient, a native Nigerian living in Nigeria suggests that it may be a universal affliction affecting all races and geographic regions.

Our patient is a 35year old man. This is in keeping with the observations of Macfadean et al in Hong Kong who reported a male preponderance amongst their patients and a peak age of occurrence in the $4^{\text {th }}$ decade of life ${ }^{4}$. Like the patients in the Hong Kong study, this man had premonitory muscle aches, but unlike them, his paralytic episodes happened while he was walking which differed from the findings in the Hong Kong study. The patients in the Hong Kong study had paralytic episodes occurring only at rest. The onset of premonitory muscle aches became warning signs for some of them to get active and work "work off" an impending attack. Trans and Reeves in Australia reported a case of similar paralysis in a gender assigned man, who was on maintenance testosterone and was also receiving interferon alpha for $\mathrm{HCV}$ infection ${ }^{23}$ while Tigas et al working in Greece observed this disorder in a patient following intravenous administration of methyl prednisolone ${ }^{24}$ which are unlike the situation in this patient who was not on any medication prior to the onset of the paralyses but has Graves disease which has been variously reported to be the commonest cause ${ }^{2,3,4}$. The hallmark of Thyrotoxic periodic paralysis is hypokalaemia ${ }^{25,26}$ but occasionally if the patient is at the recovery phase of the paralysis, the serum potassium can be normal ${ }^{26}$. The finding of a normal serum potassium level in this patient may be because he presented after the paralytic phase had passed. There have however been rare reports of normokalaemia during the paralytic phase of thyrotoxic periodic paralysis ${ }^{27,28}$.

Treatment of the acute paralytic episode is with potassium and propranolol. Further attacks are prevented by treating the underlying thyrotoxicosis. Our patient presented after the resolution of the paralytic phase though he still had muscle aches. Further attacks of paralysis did not occur after he started propranolol and later carbimazole. This is similar to the experience of Paiboonpol in Thailand ${ }^{29}$ and Frantchez et al in Uruguay $^{30}$ who noted that treatment of the background thyrotoxicosis in their patients prevented further attacks of paralysis. Whereas our patient is alive and happy a misdiagnosis may lead to an adverse outcome ${ }^{12,31}$.

\section{Conclusion:}

Thyrotoxic periodic paralysis is a rare but alarming complication of thyrotoxicosis. It is treatable if diagnosed early and managed appropriately and should be considered in the differential diagnosis of paralysis in Nigeria. It may be the explanation for the seemingly bizarre occasional complaint of recurrent inability to turn or move the limbs while awake in bed at night by some of our patients.

\section{References:}

[1] Chan A, Shinde R, Chow CC, Cockram CS, Swaminathan R. In vivo and in vitro sodium pump activity in subjects with thyrotoxic periodic paralysis. BMJ 1991; 303:1096-1099.

[2] Erem C. Thyrotoxic hypokalaemic periodic paralysis in a Turkish male with Grave's disease: a rare case report and review of of literature. Endocrine 2005; 27:63-65.

[3] Berwaerts J, Martin JJ, Mahler C. Thyrotoxic periodic paralysis, an unusual cause of hypokalaemic periodic paralysis. Acta Neurol Belg. 1996; 96:301-306.

[4] MacFadzean AJS, Yeung R. Periodic Paralysis Complicating Thyrotoxicosis in Chinese. Brit Med J. 1967;1: 450-455.

[5] Honnon MJ, Behan LA, Agha A. Thyrotoxic periodic paralysis due to excess thyroxine replacement in a caucassian. Ann Clin Biochem. 2009; 46:423.

[6] Chen YC, Fang JT, Chang TC, Chou HH. Thyrotoxic periodic paralysis in a patient abusing thyroxine for weight reduction. Ren Fail 2001; 23:139.

[7] Manoukian AA, Foote, JA, Crapo LM. Clinical and metabolic features of thyrotoxic periodic paralysis in 24 episodes. Arch Inter Med. 1999; 159:601-606.

[8] Van DAN GM, Reisman Y, Van Wieringer K. Hypokalaemic periodic paralysis: Case report and review of an oriental syndrome. Neth J Med. 1994; 49:90-97.

[9] Barahona MJ, Vinagre I,Sojo L, Cubero JM, PA-Orez A, Thyrotoxic periodic paralysis: a case report and literature review. Clin Med Res. 2009; 7:96-98.

[10] Al Jubori MA, Inkster GD, Nee PA, Andrews FJ. Thyrotoxicosis presenting as hypokallaemic paralysis in an oriental man. Ann Clin Bioch. 2006; 43:323-325.

[11] Abbasi B, Sharif Z, Sprabery LR. Hypokalaemic periodic paralysis with thyrotoxic psychosis and hypercapnic respiratory failure. Am J Med Sc 2010; 340: 147-153.

[12] Thomson MP, Princhard JK. A rare case of Thyrotoxic Periodic Paralysis Presenting to the Medical Examiner. Am J Forensic Med Pathol 2011.Aug 1[Epub ahead of print].

[13] Kodali VR, Jeffcote B, Clague RB. Tyrotoxic periodic paralysis: Case report and review of literature. J Emerg Med. 1999; 17: 4345.

[14] Sthanehwar P, Prathibha R, Yap SF. Thyrotoxic periodic paralysis: a report of 3 Malaysian cases and a review of its pathology. Malays J Pathol 2005; 27:29-32.

[15] Majhi S, Metha KD, Rohil V.Thyrotoxic hypokalaemic periodic paralysis in a man from Nepal. BMJ Case Rep 2009; 5: 1836.

[16] Seshadri P, Frank KD, Iqbal N. Thyrotoxic hypokalemic periodic paralysis in a Native American patient. Endocr Pract. 2002; 8: 362-363.

[17] Zumo LA, Terzien C, Brannan T. Thyrotoxic periodic paralysis in a Hispanic male.

J Natl Med Assc. 2002; 94:383-386

[18] Antonello IC, Antonello VS, de Los Santos CA, de Almeida N, d' Avila DO. Thyrotoxic hypokalemic paralysis: a life threatening syndrome. European J Emerg Med.1999; 16:43-44. 
[19] Messina G, Savina A. A rare case of hypokalemic thyrotoxic periodic paralysis in a caucassian patient with Basedow's disease. Ricent I Prog Med .1999;90: 392-393.

[20] Kalburova,F, Petrov D, Ilieva K, Belovezhdov N. Hypokalaemic periodic paralysis Iin thyrotoxicosis. Vutr Boles. 1989; 28: 73 76.

[21] Norris KC, Levine B, Ganesan K. Thyrotoxic periodic paralysis associated with hypokalaemia and hypophosphataemia . Am J Kidney DIS. 1996; 28:270-273.

[22] Ober KP. Thyrotoxic periodic paralysis in the United States. Report of 7 cases and review of literature. Medicine 1992; 71: 109120.

[23] Tran HA, Reeves GE .Hepetitis C infection and thyrotoxic periodic paralysis-a novel use of an old drug. Am J Med Sci 2008; 336:515-518.

[24] Tigas S, Papachilleos P, Ligros N, Andrikoula M,Tsatsoulis A. Hypokalaemic paralysis following administration of intravenous methyl prednisolone in a patient with Grave's thyrotoxicosis and ophthalmopathy. Hormones 2011;10: 313-316.

[25] Porthiwala P, Levine SN. Analytical review: thyrotoxic periodic paralysis: a review. J Intensive Care Med. 2010;25: 71-77.

[26] Kung AW. Clinical review: Thyrotoxic Periodic Paralysis: a diagnostic challenge. J Clin Endocrinol. Metab2006; 91:2490-2495.

[27] Gonzalez-Trevino O, Rosas- Guzman. Normokalaemic thyrotoxic periodic paralysis: A new therapeutic strategy. Thyroid 1999;9: 61-64.

[28] Wu CC, Chau T, Cheng CJ, Lin SJ. Anrecognised cause of paralysis in ED:Thyrotoxic normokalaemic periodic paralysis. Am J Emerg Med 2003;71:-73.

[29] Paiboonpol S. Hypokalaemic periodic paralysis as a manifestation of Thyrotoxic of Thyrotoxic osis. J. Med. Assoc. Thai. 2008;91: 1331-1336.

[30] Frantchez V, Valino J,Carracellos, Dufrachou C. Thyrotoxic hypokalemic periodic paralysis: report of a case. Med Chil 2010; 138:1427-1430.

[31] Chen DY, Scheider, Zang XS, He ZM, Chen TH. Fatality after Cardiac Arrest in Thyrotoxic Periodic Paralysis due Profound Hypokalaemia Resulting from Intravenous Glucose Adminitration and Inadequate Potassium Replacement. Thyroid 2012. May $24[$ E pub ahead of print]. 